\title{
The Single Ventricle Reconstruction trial: The gift that keeps on giving
}

\author{
Robert D. B. Jaquiss, MD
}

From the Division of Cardiovascular and Thoracic Surgery, Department of Surgery, Duke University School of Medicine, Durham, NC.

Disclosures: Author has nothing to disclose with regard to commercial support.

Received for publication Sept 19, 2015; accepted for publication Sept 23, 2015; available ahead of print Oct 26, 2015.

Address for reprints: Robert D. B. Jaquiss, MD, Division of Cardiovascular and Thoracic Surgery, Duke University School of Medicine, DUMC 3474, Durham, NC 27710 (E-mail: Robert.jaquiss@duke.edu).

J Thorac Cardiovasc Surg 2016;151:676-7

$0022-5223 / \$ 36.00$

Copyright (c) 2016 by The American Association for Thoracic Surgery

http://dx.doi.org/10.1016/j.jtcvs.2015.09.095

For those who care for children born with hypoplastic left heart syndrome and associated conditions, the Single Ventricle Reconstruction trial (SVRT) is a landmark study and a vital source of continuing information. ${ }^{1}$ In the simplest sense, the SVRT was designed to compare outcomes between children undergoing a Norwood procedure who received a right ventricle-pulmonary artery conduit (RVPAS) and those undergoing a Norwood procedure who received a modified Blalock-Taussig shunt, with specific focus on heart transplant-free survival. The initial report from the study demonstrated a statistically significant transplant-free survival advantage at 12 months of follow-up in patients with the RVPAS. ${ }^{2}$ As the SVRT cohort has been followed up, however, subsequent interval reports have shown that the patients with RVPAS placement had more pulmonary artery distortion requiring more interventions, more right ventricular dysfunction, and more tricuspid valve regurgitation. ${ }^{3,4}$ Furthermore, by 3 years the transplant-free survival advantage of the RVPAS was no longer significant. ${ }^{5}$ Although these findings may have tempered the initial enthusiasm for the RVPAS generated by the 12-month results, the study investigators have continued their careful follow-up to determine whether important differences between the 2 types of shunt will emerge later. In the most recent report, written by Ravishankar and colleagues ${ }^{6}$ and appearing in this issue of the Journal, which is derived from the time of the Fontan operation, the SVRT investigators found that the RVPAS group did not have worse clinical outcomes, which was counter to their study hypothesis, as based on the worse right ventricular function in that group.

Perhaps the most encouraging findings in the study of Ravishankar and colleagues ${ }^{6}$ are the remarkably excellent early outcomes currently observed with the Fontan operation in both cohorts, with only 1 operative death and no takedown operations or postoperative referrals for transplant among 327 patients. This is especially notable in that such stellar results were obtained for patients with hypoplastic left heart syndrome, who are generally

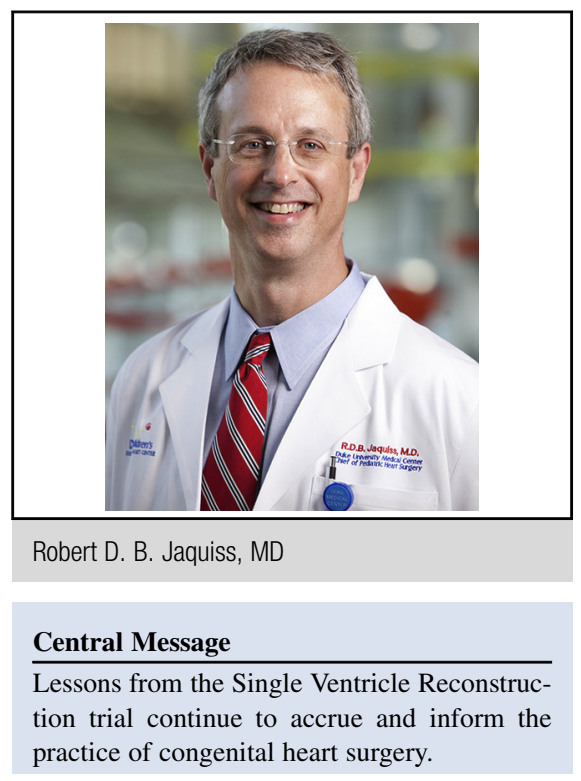

See Article page 669

considered to be at higher risk than patients with single left ventricle morphology. It is worth pointing out that the hypothesis that Ravishankar and colleagues ${ }^{6}$ chose to test hinged not on weighty questions of mortality or major morbidity but on the relatively pedestrian question of length of stay. This is not to say that the weightier metrics are unimportant, but simply to point out that death and major complications no longer haunt the prospect of Fontan surgery for most patients, at least at the SVRT study sites. Several features of the overall SVRT Fontan cohort are worthy of mention, lest the results be generalized more broadly to the Fontan operation. These were patients considered to be at very good risk before the Fontan operation, with low ventricular end-diastolic pressure $(8.3 \mathrm{~mm} \mathrm{Hg})$ and low transpulmonary gradients $(3.4 \mathrm{~mm}$ $\mathrm{Hg}$ ), and only a minority had important pulmonary artery abnormalities (29\%). Nonetheless, a very high proportion $(87 \%)$ of patients had fenestrations performed at the time of the Fontan operation.

For all that has been learned and all that may yet be learned from the SVRT cohort, there are many question about the management of such patients that will not be revealed from further analysis of these patients. We will not learn about the optimal timing of Fontan operations, the optimal forms of second- and third-stage reconstructions (hemi-Fontan and lateral tunnel vs bidirectional Glenn 
and extracardiac conduit), and we will not have answers about when to fenestrate. Another important point is that the RVPAS as performed during the period of enrollment in the SVRT has undergone significant modificationsuse of externally ringed conduits, simplified techniques for proximal anastomosis, and even the identification of the superiority of right sided placement of the RVPAS. ${ }^{7-9}$ At present, it is not clear how to incorporate these changes with the information gleaned from the SVRT, and it seems highly unlikely that the trial will be repeated with RVPAS “2.0."

A seldom-discussed aspect of the SVRT is the relevance of the primary outcome measure: transplant-free survival. The rationale for this choice is quite apparent if the goal of interventions is to preserve the native heart as a functional pump; in such a construct, a transplant represents failure. On the other hand, if the goal of interventions is to preserve the life of the patient, the end point of greatest interest to parents and families, then "simple" survival may be more important. In this construct, transplant may be simply viewed as another stage of palliation. Now that the difference in the SVRT primary end point has diminished to below the threshold of statistical significance with the aging of the cohorts, it might be reasonable for the investigators to consider a reanalysis of their data to answer a simple question: how many of each cohort are alive, regardless of transplant status? This is relevant because of the generally excellent outcomes of transplant in young children. ${ }^{10}$

In summary, the study of Ravishankar and colleagues ${ }^{6}$ is reassuring in that patients with RVPASs, worse though their right ventricular function may be, fare as well as their counterparts with modified Blalock-Taussig shunts early after the Fontan operation. Whether this state will continue through mid- and long-term Fontan follow-up remains to be seen, and we await further dispatches from the SVRT investigators.

\section{References}

1. Ohye RG, Gaynor JW, Ghanayem NS, Goldberg CS, Laussen PC, Frommelt PC, et al; Pediatric Heart Network Investigators. Design and rationale of a randomized trial comparing the Blalock-Taussig and right ventricle-pulmonary artery shunts in the Norwood procedure. J Thorac Cardiovasc Surg. 2008;136:968-75.

2. Ohye RG, Sleeper LA, Mahony L, Newburger JW, Pearson GD, Lu M, et al; Pediatric Heart Network Investigators. Comparison of shunt types in the Norwood procedure for single-ventricle lesions. N Engl J Med. 2010;362:1980-92.

3. Aiyagari R, Rhodes JF, Shrader P, Radtke WA, Bandisode VM, Bergersen L, et al; Pediatric Heart Network Investigators. Impact of pre-stage II hemodynamics and pulmonary artery anatomy on 12-month outcomes in the Pediatric Heart Network Single Ventricle Reconstruction trial. J Thorac Cardiovasc Surg. 2014;148:1467-74.

4. Frommelt PC, Gerstenberger E, Cnota JF, Cohen MS, Gorentz J, Hill KD, et al; Pediatric Heart Network Investigators. Impact of initial shunt type on cardiac size and function in children with single right ventricle anomalies before the Fontan procedure: the Single Ventricle Reconstruction extension trial. J Am Coll Cardiol. 2014;64:2026-35.

5. Newburger JW, Sleeper LA, Frommelt PC, Pearson GD, Mahle WT, Chen S, et al; Pediatric Heart Network Investigators. Transplantation-free survival and interventions at 3 years in the Single Ventricle Reconstruction trial. Circulation. 2014;129:2013-20.

6. Ravishankar C, Gerstenberger E, Sleeper LA, Atz AM, Affolter JT, Bradley TJ, et al; Pediatric Heart Network Investigators. Factors affecting Fontan length of stay: results from the Single Ventricle Reconstruction trial. J Thorac Cardiovasc Surg. 2016;151:669-75.

7. Bentham JR, Baird CW, Porras DP, Rathod RH, Marshall AC. A reinforced right-ventricle-to-pulmonary-artery conduit for the stage-1 Norwood procedure improves pulmonary artery growth. J Thorac Cardiovasc Surg. 2015;149: 1502-8.e1.

8. Tweddell JS, Mitchell ME, Woods RK, Spray TL, Quintessenza JA. Construction of the right ventricle-to-pulmonary artery conduit in the Norwood: the "dunk" technique. Oper Tech Thorac Cardiovasc Surg. 2012;17:81-98.

9. Mroczek TM, Zurek R, Morka A, Jarosz J, Szymanska K, Skalski JH. The modification of right ventricle to pulmonary artery conduit for Norwood procedure reduces the number of unintended shunt-related events. J Thorac Cardiovasc Surg. 2015. In press.

10. Benden C, Goldfarb SB, Edwards LB, Kucheryavaya AY, Christie JD Dipchand AI, et al. International Society for Heart and Lung Transplantation. The registry of the International Society for Heart and Lung Transplantation: seventeenth official pediatric lung and heart-lung transplantation report-2014 focus theme: retransplantation. J Heart Lung Transplant. 2014;33:1025-33. 